ЯНИЦКИЙ Олег Николаевич - доктор философских наук, профессор; главный научный сотрудник Института социологии ФНИСЦ РАН (117218, Россия, г. Москва, ул. Кржижановского, 24/35, кopn. 5; oleg.yanitsky@yandex.ru)

\title{
ПЕРЕХОД НА «ЦИФРУ» И ЗАДАЧИ НАУКИ И ОБРАЗОВАНИЯ
}

Аннотация. Цель статьи - проанализировать влияние четвертой промышленной революции (HTP-4) на российское общество, его институты науки и образования. Автор излагает характеристики HTP-4 как нового способа производства и организации общественной жизни; определяет положение России в системе глобальных геополитических координат; анализирует ключевые задачи перехода страны к информационному обществу; формулирует неотложные проблемы общественных наук и образования; рассматривает риски и опасности, возникающие в условиях нарастающего геополитического давления на нашу страну.

Ключевые слова: агент, геополитика, гибридная война, глобализация, информационное общество, наука, НTP-4, образование, риск, технологии, российское общество

Перед нашим обществом и изучающими его науками сегодня стоят несколько основных задач:

1) определить, где наше общество находится в глобальной системе геополитических координат;

2) обозначить неотложные проблемы перехода России к информационному обществу, обусловленные НТР-4;

3) выявить актуальные задачи развития общественных наук и связанной с ними системы образования;

4) обсудить, как осуществить такой переход в условиях санкций и других средств геополитического давления на наше общество.

Рассмотрим их последовательно.

Исходные теоретические предпосылки. НТР-4 - это не просто создание информационных сетей, охватывающих мир и нашу страну. НТР-4 - это создание нового способа производства, новой институциональной структуры общества и мира в целом, ключевым продуктом производства и потребления которых является информация. Речь идет не только и не столько об информировании общества, сколько о создании новых технологий и социальных структур на основе производства нового междисциплинарного знания, касающегося любых отраслей современного производства и общественной жизни.

Согласно М. Кастельсу, следует различать знания, их накопление, осмысление, трансформацию и информацию, которую можно организовать, упаковать и передать реципиенту с целью использования для развития производства и человека. «Генерирование, обработка и передача информации стали фундаментальными источниками производительности и власти» [Кастельс 2000: 39-42]. Еще одно важное замечание: «в отличие от любой иной революции, ядро трансформации, которую мы переживаем теперь, связано с технологиями обработки информации и коммуникации». И далее, «новые информационные технологии являются не просто инструментами, которые нужно применить, но процессами, которые нужно разрабатывать» [Кастельс 2000: 50-51]. Кастельс предвидел, что будет несколько информационно-технологических революций - вторая, технико-биологическая, уже идет на наших глазах, за ней идет третья, геоклиматическая, и т.д.

Наконец, важно, что власть не исчезает, «она становится вписанной на фундаментальном уровне в культурные коды, посредством которых люди и институты 
представляют жизнь и принимают решения, включая политические решения». Поэтому борьба за власть в основном ведется в средствах массовой информации [Кастельс 2000: 502]. Названные факты означают, что никакое общество не может развиваться, если оно не использует междисциплинарные подходы, позволяющие интегрировать разрозненные факты и процессы для принятия решений и выстраивать комплексную стратегию своего развития.

Как всякая новация, информационная революция имеет свои негативные стороны: непрерывное ускорение социально-экономических процессов, сжатие рынка труда, сбои в работе информационных систем, хакерские атаки и т.д. Но главное - полное разрушение приватности человеческой жизни, возможность проникновения в его мысли и чувства и изменение их в нужном для экономических или политических агентов направлении. Сегодня уже созданы многочисленные службы противодействия «информационной инфильтрации» человеческого сознания и поведения, но и они не могут полностью гарантировать безопасность человека.

1. Гдемы находимся в глобальной системе координат? С моей точки зрения, мы находимся где-то посередине. Это означает, как отмечают ведущие российские экономисты, вероятность ухудшения экономического положения вследствие недостаточности инвестиций, сокращения рынка труда, роста разрыва между бедными и богатыми, все большего распространения коррупции и «теневой экономики». А. Кудрин, Э. Набиуллина, Г. Греф и другие экономисты и эксперты предрекают в ближайшем будущем экономический кризис и, возможно, даже дефолт. В этом смысле мы все меньше отличаемся от большинства стран «третьего мира».

Основная масса населения страны недовольна снижением уровня жизни, ростом тарифов на коммунальные услуги, пенсионной реформой, растущим увеличением разного рода новых ограничений и норм, ожидаемым, по мнению некоторых аналитиков, очередным обвалом рубля.

Одновременно, если посмотреть на глобальную ситуацию с экономической точки зрения, США, Китай, ЕС и Индия все быстрее уходят вперед. США, подобно Великобритании в прошлом, пытаются вернуть себе роль державы, управляющей всем миром, причем ведут достаточно агрессивную внешнюю политику. За исключением отечественного ВПК, который не только возрождается, но и быстро развивается, я бы назвал сложившуюся сегодня в России социально-экономическую ситуацию близкой к критической вследствие ее неготовности к предстоящим переменам.

Однако если Россия сегодня включена в глобальную информационную сеть, то возникает еще один принципиальный вопрос, какова общая диспозиция сил в ней, т.е. кто наши союзники и противники? Хотя информационная система охватывает весь мир, контент, производимый ее участниками, по отношению к поставленным выше задачам разный: дружественный, нейтральный, враждебный. Неприемлемой является и та форма «дружбы», которая нацелена на подчинение нашего общества интересам глобальных стейкхолдеров и групп враждебно настроенных к нам стран Запада. А нам в первую очередь нужны союзники и партнеры, готовые совместно развивать информационное производство.

Что же касается российской социологии, то она, если судить по материалам двух последних международных событий - Социологического форума в Вене (2016 г.) и Международного социологического конгресса в Торонто (2018 г.), продолжает развиваться вровень со многими другими странами мира. Однако она серьезно отстает от них в двух планах: в разработке концепции НТР-4 и созданной на ее основе модели информационного общества и в пропаганде 
своих достижений. Политики и ученые чаще всего используют данные социологических исследований лишь для подтверждения или критики уже принятых политических решений. То есть, публичная социология как часть геополитики все еще сильно отстает от социологии как науки.

Концепция НТР-4 разрабатывалась мною и другими российскими социологами начиная с 1970-х гг. [Яницкий 1972]. Однако тогда внедрить ее в государственную политику не удалось. Сегодня наблюдается технологический крен в интерпретации НТР-4. Например, акцентируется задача «совершенствования технологии стратегического планирования системы обеспечения национальной безопасности» России, но ничего не говорится о технологиях защиты самого населения страны и сохранения среды его обитания. Авторы приглашают к обсуждению «уполномоченные органы власти», но ничего не говорят о роли самого населения и гражданских организаций [Никитенко, Синицын, Сергеев 2018].

Наконец, с моей точки зрения, глобальная гибридная война уже началась. Вот ее основные отличия. Если экономическая и политическая борьба ведутся в основном легальными средствами, то гибридная война - любыми. Борьба нацелена на выигрыш, на создание новых технологий и рынков, социальных инноваций, гибридная война - на разрушение и подавление вероятного противника. Наконец, гибридная война, если побеждает в борьбе с внешними врагами, переключается на подавление внутренних оппонентов. В этом смысле гибридная война есть наиболее жестокая форма «внутривидовой» борьбы.

2. Актуальные проблемы перехода к информационному обществу. По моему мнению, сегодня российское общество должно одновременно решать четыре задачи. Первая - постепенно уменьшать зависимость экономики, политики и жизни всего населения от нефтегазового сектора, тем более что в этом плане на РФ оказывается все возрастающее давление со стороны США и ЕС. Очевидно, что такой постепенный процесс возможен только при одновременном развитии высокотехнологичных и высокодоходных отраслей производства. Однако для этого требуются политическая воля, немалые финансовые и интеллектуальные ресурсы и, конечно, время. В информационную эпоху время становится одним из ключевых ресурсов.

Вторая, тесно связанная с первой, задача - это восстановление промышленного потенциала страны, во многом утраченного за годы перестройки. Эта задача гораздо сложнее, потому что, с одной стороны, нужны кадры, деньги и ресурсы, а с другой - для восстановления этого потенциала требуется соответствующая инфраструктура, т.е. опять же будут нужны кадры, деньги и ресурсы. С моей точки зрения, здесь необходимо начать с тех предприятий и кадров, которые необходимы для решения третьей задачи, т.е. для кадрового, ресурсного и иного обеспечения перехода на рельсы НТР-4.

Третья задача - это собственно переход к производству и социальному воспроизводству страны, основанным на принципах и институциях информационного общества. Эта часть переходного периода наиболее сложна и болезненна для любого общества, т.к. связана с изменением практически всех сторон общественной жизни: сфер труда, быта, досуга, образования, социальной помощи, направления и скорости миграционных процессов и т.д.

Недостаточность ресурсов для решения этой задачи и сопротивление сложившейся институциональной системы приведет, по моему мнению, к необходимости мобилизационного периода, который будет характеризоваться ужесточением государственного регулирования бизнеса, общественной и частной жизни. Осложнит этот переходный период также старый жилой фонд и ветхая дорожная и иная инфраструктура. Вполне вероятно также, что произойдет 
ухудшение качества жизни как вследствие недостатка внутренних ресурсов для этой новой перестройки, так и в результате санкций и других ограничительных мер, налагаемых на нашу страну извне.

Четвертая задача - это осуществление названных выше мер в условиях гибридной войны, которая ведется против нас консолидированным Западом экономическими, политическими и медиасредствами. Цель гибридной войны - разрушение экономической и политической структуры страны и подчинение российского общества этим консолидированным интересам. Пора, наконец, всем осознать, что гибридная война - это не что-то резко отличное от мирного времени. Это сегодня уже перманентное состояние как глобального сообщества, так и отдельных его частей.

3. Проблемы развития общественных наук и образования. Не только в России, но и во многих других странах мира происходит падение престижа общественных наук и их замещение геополитическими науками и высказываниями мировых лидеров. Не только население, но и политическую элиту приучают верить только мнению публичных фигур («говорящих голов»). Население теряет доверие к существующим политическим институтам и ориентируется на «коллективное мнение», вырабатываемое в социальных сетях.

На какую из интегрированных наук Запада мы можем ориентироваться более всего? Думаю, в первую очередь - на европейскую социологию, тем более что большинство работ ее лидеров переведены на русский язык. Я имею в виду работы 3. Баумана, У. Бека, М. Кастельса, А. Турэна и многих других. Особо я бы выделил работы Кастельса, т.к. он уже много лет разрабатывает концепцию глобального информационного общества, в разработке которой российские социологи отстали как минимум на 20-30 лет. Это не их вина, т.к. само общество застряло на уровне третьей, т.е. индустриальной, революции.

Хуже другое. Наши общественные науки, в отличие от естественных и технических, не разрабатывают (не хотят видеть?) быстро развивающийся процесс междисциплинарного взаимодействия, забывая, что многие видные социологи и психологи (3. Фрейд, Т. Парсонс, И. Гоффман) были поначалу врачами. Блестящий пример такого комплексного подхода дал в начале ХХ в. П. Сорокин в работе «Голод как фактор...» - работе, которую буквально по частям восстановили сотрудники Института социологии РАН. Не меньший вклад внесли в разработку комплексного подхода к анализу общественных явлений Д.С. Лихачев, М.М. Бахтин и многие другие русские ученые-гуманитарии.

Однако этот тренд, соответствующий интегративному характеру информационной революции, не находит должного отклика в системе преподавания обществоведческих дисциплин. Сегодня по своей методике преподавание общественных дисциплин фактически повторяет «классно-урочную» систему средней школы. В частности, высшее социологическое образование не ориентировано на решение тех задач, о которых речь шла выше. Я уже не раз убеждался в том, что студентов мало интересует сам процесс социологического исследования, они, как правило, уже где-то пристроились (обычно в недрах административных структур) и ждут только получения заветных «корочек». На семинарах РОСа или других общественных организаций они молча «отбывают свой номер», почти никогда не задавая вопросов, т.к. «производственную практику» они проходят не в поле, не в «гуще жизни», как говорил наш великий ученый В.И. Вернадский, а в стенах тех же гуманитарных факультетов.

Если взглянуть на этот процесс с политической точки зрения, то мы имеем дело с властью факта, т.е. с властью существующей системы подготовки гуманитарных кадров, которая никак не соответствует непрерывно усложняющемуся и ускоряющемуся процессу социальных и технологических перемен. 
4. Как осуществить такой переход в условиях геополитического давления? Здесь главная проблема - предотвратить возможность нанесения обезоруживающего удара консолидированным Западом. Но это задача российских военных стратегов и военно-промышленного комплекса.

Теперь о целях такого объединенного геополитического давления на Россию. Его главная цель проста: устранить Россию с глобальной арены и затем использовать ее природные ресурсы. Население нашей страны этому глобальному игроку не нужно, расчет делается на то, что оно или быстро вымрет, или будет рассеяно по огромной территории и потому не представляет для этого глобального альянса никакой опасности. А наиболее ценные научные и иные кадры эмигрируют в США или в ЕС.

Для этого альянса опасность состоит прежде всего в борьбе за территорию и ресурсы с другими глобальными игроками. Или, что еще хуже для него, это союз России с Китаем или с рядом региональных держав, например с Казахстаном, против него. Наконец, в действительности этот альянс не столь «консолидирован», у него тоже есть противники - те же Китай и Индия, которые не хотят вновь стать колониями США, Великобритании или НАТО.

Теперь об инструментах, которые используются консолидированным Западом для достижения своих целей. Ведение гибридной войны против России/СССР/ РФ - давняя стратегия и тактика США и ряда европейских держав. НТР-4, давшая миру такое мощное оружие, как глобальные информационные сети, лишь многократно усилила возможность ведения гибридных войн.

На мой взгляд, главная опасность состоит в растущей изоляции РФ от экономики и политики остального мира посредством ее отключения от участия в формировании глобальной геополитики, в частности от международной платежной системы SWIFT и от возможности пользования международным софтом, что соответственно, требует создания своего собственного софта. То есть, дезинтеграция с мировой экономикой - главная опасность, за которой идут тотальное импортозамещение, огосударствление экономики, рост цен, падение уровня жизни населения, рост уровня неплатежей и т.д. Нельзя забывать и о негативной психологической атмосфере, создаваемой этой изоляцией. Наконец, само ожидание этих и других угроз плюс общая неопределенность ближайшего будущего суть также глобальные факторы снижения социальной активности бизнеса и населения.

Поэтому если включенность в международные экономические и иные сети будет ограничена, значит, надо развивать и укреплять сетевые структуры на уровне макрорегионов. Но это будет возможным только в том случае, если обмен между ними знаниями, технологиями и т.д. будет взаимно выгодным. Закон разделения труда, равно как и кооперации усилий, никто не отменял. Кстати, и внутрирегиональное сотрудничество, например между наукой, вузами и территориальными организациями, базирующееся на сетевом взаимодействии, взаимовыгодно [Зборовский, Амбарова 2018]. Справедливой критике подвергается модель полной подчиненности управления сложными системами множеству институционально закрепленных кодов и правил, и обосновывается необходимость перехода к акторской модели управления. В частности, отмечается необходимость мобилизационной модели действия в критических обстоятельствах [Аксенова 2018]. В таких обстоятельствах при дефиците времени на спасательные работы необходимо опираться не только на силы МЧС, но и на гражданские организации, которые не могут и не должны полностью зависеть от государства.

Bыводы. Под воздействием НТР-4 изменяется не только сам способ производства, но и вся диспозиция сил и отношений, формирующих глобальный 
миропорядок. Сегодня российское общество находится в процессе перехода на рельсы информационного общества, занимая некоторое срединное положение на шкале координат идущей сегодня трансформации этого миропорядка. Для России сложность этого переходного периода обусловлена несколькими обстоятельствами: необходимостью уменьшения зависимости от нефтегазовой индустрии, интенсивного развития новой индустрии, основанной на цифровых технологиях, необходимостью перестройки системы образования, а также усилением санкционного и другого геополитического давления на российское общество извне.

Исходя из сказанного, полагаю, что Россия и мир в целом уже вошли в состояние перманентной гибридной войны, которая ведется самыми разными средствами. В этих условиях нам предстоит некий переходный период, который будет иметь мобилизационный характер. Это обусловлено необходимостью одновременного решения задач создания новой индустрии и ее инфраструктуры, основанной на информационных технологиях, сохранения существующего социального потенциала общества, реструктуризации политических институтов, а также развития междисциплинарных исследований и соответствующих методов образования и обучения. Это, в свою очередь, означает перестройку инфраструктуры этих институтов с привлечением потенциала организаций гражданского общества, что поможет преодолеть «технократический уклон», наметившийся в ряде работ отечественных и зарубежных специалистов.

\section{Список литературы}

Аксенова О.В. 2018. Модели управления в России и на Западе: риски и перспективы развития. - Россия реформирующаяся: ежегодник. Вып. 16 (отв. ред. М.К. Горшков). М.: Новый хронограф. С. 348-372.

Зборовский Г.Е., Амбарова П.А. 2018. Университеты, которые могут изменить себя и макрорегион. - Россия реформирующаяся: ежегодник. Вып. 16 (отв. ред. М.К. Горшков). М.: Новый хронограф. С. 373-394.

Кастельс М. 2000. Информационнаяэпоха (пер. сангл. подред. О.И. Шкаратана). М.: Изд-во ГУ ВШЭ. 607 с.

Никитенко Е.Г., Синицын И.М., Сергеев Н.А. 2018. Проблемы совершенствования технологии стратегического планирования в перспективной системе обеспечения национальной безопасности России. - Власть. № 7. С. 52-65.

Яницкий О.Н. 1972. Социально-информационные процессы в обществе и урбанизация. - Урбанизация, НТР и рабочий класс (отв. ред. О.Н. Яницкий). М.: Наука. С. 76-96.

YANITSKY Oleg Nikolaevich, Dr.Sci. (Philos.), Professor; Chief Researcher of the Sociological Institute - branch of the Federal Center of Theoretical and Applied Sociology, Russian Academy of Sciences (bld. 5, 24/35 Krzhizhanovskogo St, Moscow, Russia, 117218; oleg.yanitsky@yandex.ru)

\section{SHIFT TOWARD THE INFORMATION SOCIETY AND URGENT TASKS OF SOCIAL SCIENCES AND EDUCATION}

Abstract. The aim of the article is to analyze an impact of the fourth industrial revolution (hereafter - the STR-4) and on Russian society as well as on the institutions of science and education. The author lays down such main features of the STR-4 as the new mode of production and organization of social life and defines a place of Russia in a current disposition of global 
geopolitical coordinates. He also analyzes the key issues of Russia's transition toward the information society and formulate the urgent issues of restructuring of social sciences and education and the risks and threats of growing geopolitical pressure on Russian society. Russia is now entering into a certain transition period burdened with the international and domestic conflicts. Therefore, civil society and its organizations should participate of in this process.

Keywords: agent, conflict, geopolitics, globalization, information society, science and education, risk, technologies, STR-4, transition period, Russian society

ШИЛОВ Владимир Викторович - кандидат исторических наук, заведующий кафедрой общенаучных дисциплин Березниковского филиала Пермского национального исследовательского политехнического университета (618400, Россия, Пермский край, г. Березники, ул. Химиков, 10, каб. № 205; vvs595959@таil.ru); член правления Российского общества социологов (Пермское отделение)

\title{
РОЛЬ ИНТЕРНЕТА В ПОЛИТИЧЕСКОЙ СФЕРЕ СОЦИУМА
}

\author{
Часть 2
}

Аннотация. В статье анализируется роль компьютерных технологий; показываются их сильные и слабые стороны в процессе формирования ценностных установок личности в эпоху цифровых коммуникаций. На основе статистических данных, результатов социологических опросов автор выявляет значение Интернета в повседневной жизни политиков, молодежи и людей старших возрастов и делает вывод о слабом использовании властными структурами платформ социальных медиа в процессе развития гражданского общества, становления правового государства и формирования политической культуры граждан.

Ключевые слова: информационные потоки, избирательная кампания, депутаты, молодежь, люди старших возрастов, культура постиндустриального общества, гражданское общество, правовое государство

$\mathrm{O}$ собый интерес исследователей вызывает подрастающее поколение, которое в скором времени будет определять вектор развития российского общества, хотя, как известно, политтехнологи в период предвыборных кампаний отдают предпочтение людям старших возрастов как самому массовому электорату.

С этой целью весной 2018 г. нами был проведен опрос о роли Интернета в повседневной жизни молодого поколения и людей старших возрастов. Респондентов-пенсионеров мы взяли также и для сравнительного анализа, т.к. их мировоззрение уже сформировано и знаний в сфере $I T$-технологий по объективным причинам у них меньше, чем у респондентов, относящихся к молодому поколению.

Анкетный опрос проводился в г. Березники Пермского края - крупном индустриальном центре Верхнекамья, втором по социально-экономическому потенциалу городе Западного Урала (после краевого центра г. Перми) с численностью около 150 тыс. жителей. Респондентами 1-й группы выступили студенты Березниковского филиала Пермского национального исследовательского политехнического университета (БФ ПНИПУ), Березниковского политехнического техникума (БПТ), Березниковского медучилища (техникум) и Березниковского строительного техникума (БСТ). Всего опрошены 220 респондентов; мужчин - 133 чел. (60\%), женщин - 87 чел. (40\%). Средний возраст опрашиваемых 21,3 года.

Респондентами 2-й группы выступили пенсионеры Березниковского городского округа из Совета ветеранов педагогического труда, Совета ветеранов профтехобразования, Совета ветеранов ПАО «Уралкалий», Совета ветеранов 